\title{
Trabeculated Myocardium in Hypertrophic Cardiomyopathy: Clinical Consequences
}

\author{
José David Casanova ${ }^{1}$, Josefa González Carrillo ${ }^{2,3,4} \mathbb{C}^{\text {, Jesús Martín Jiménez }}{ }^{2,3}{ }^{\circledR 0}$, \\ Javier Cuenca Muñoz ${ }^{1}$, Carmen Muñoz Esparza 2,3,4 , Marcos Siguero Alvárez ${ }^{5,6}$, \\ Rubén Escribá ${ }^{7,8}$, Esther Burillo Milla ${ }^{2}$, José Luis de la Pompa 5,6 (D) Ángel Raya 7,8,9 (D), \\ Juan Ramón Gimeno ${ }^{2,3,4, *(D)}$, María Sabater Molina ${ }^{2}$ and Gregorio Bernabé García ${ }^{1}$ (D) \\ 1 Departamento de Ingeniería y Tecnología de Computadores, Universidad de Murcia, Espinardo, \\ 30100 Murcia, Spain; josedavid.casanova@um.es (J.D.C.); jcuenca@um.es (J.C.M.); \\ gbernabe@ditec.um.es (G.B.G.) \\ 2 Unidad CSUR de Cardiopatías Familiares, Servicio de Cardiología, Hospital Universitario Virgen de la \\ Arrixaca, Universidad de Murcia, El Palmar, 30120 Murcia, Spain; josegonca.alarcon@gmail.com (J.G.C.); \\ jmj59c@gmail.com (J.M.J.); carmue83@gmail.com (C.M.E.); esbumi@hotmail.com (E.B.M.); \\ mariasm@um.es (M.S.M.) \\ 3 Instituto Murciano de Investigación Biosanitaria (IMIB), El Palmar, 30120 Murcia, Spain \\ 4 European Reference Networks (Guard-Heart), Red de Investigación Cardiovascular (CIBERCV), Instituto de \\ Salud Carlos III, El Palmar, 30120 Murcia, Spain \\ 5 Intercellular Signalling in Cardiovascular Development and Disease Laboratory, Centro Nacional de \\ Investigaciones Cardiovasculares (CNIC), Melchor Fernández Almagro 3, 28029 Madrid, Spain; \\ marcos.siguero@cnic.es (M.S.A.); jlpompa@cnic.es (J.L.d.1.P.) \\ 6 Centro de Investigación Biomédica en Red de Enfermedades Cardiovasculares (CIBERCV), Instituto de \\ Salud Carlos III, 28029 Madrid, Spain \\ 7 Regenerative Medicine Program, Bellvitge Biomedical Research Institute (IDIBELL) and Program for Clinical \\ Translation of Regenerative Medicine in Catalonia (P-CMRC), Hospital Duran i Reynals, Hospitalet de \\ Llobregat, 08908 Barcelona, Spain; rescriba@idibell.cat (R.E.); araya@idibell.cat (Á.R.) \\ 8 Centre for Networked Biomedical Research on Bioengineering, Biomaterials, and \\ Nanomedicine (CIBER-BBN), 28029 Madrid, Spain \\ 9 Institució Catalana de Recerca i Estudis Avançats (ICREA), 08010 Barcelona, Spain \\ * Correspondence: jgimeno@secardiologia.es; Tel.: +34-968-369-558
}

Received: 9 September 2020; Accepted: 27 September 2020; Published: 30 September 2020

Abstract: Aims: Hypertrophic cardiomyopathy (HCM) is often accompanied by increased trabeculated myocardium (TM) - which clinical relevance is unknown. We aim to measure the left ventricular (LV) mass and proportion of trabeculation in an HCM population and to analyze its clinical implication. Methods and Results: We evaluated 211 patients with HCM (mean age $47.8 \pm 16.3$ years, $73.0 \%$ males) with cardiac magnetic resonance (CMR) studies. LV trabecular and compacted mass were measured using dedicated software for automatic delineation of borders. Mean compacted myocardium (CM) was $160.0 \pm 62.0 \mathrm{~g}$ and trabecular myocardium (TM) $55.5 \pm 18.7 \mathrm{~g}$. The percentage of trabeculated myocardium (TM\%) was $26.7 \% \pm 6.4 \%$. Females had significantly increased TM\% compared to males $(29.7 \pm 7.2$ vs. $25.6 \pm 5.8, p<0.0001)$. Patients with LVEF $<50 \%$ had significantly higher values of TM\% $(30.2 \% \pm 6.0 \%$ vs. $26.6 \% \pm 6.4 \%, p=0.02)$. Multivariable analysis showed that female gender and neutral pattern of hypertrophy were directly associated with $\mathrm{TM} \%$, while dynamic obstruction, maximal wall thickness and LVEF\% were inversely associated with $\mathrm{TM} \%$. There was no association between TM\% with arterial hypertension, physical activity, or symptoms. Atrial fibrillation and severity of hypertrophy were the only variables associated with cardiovascular death. Multivariable analysis failed to demonstrate any correlation between TM\% and arrhythmias. Conclusions: Approximately $25 \%$ of myocardium appears non-compacted and can automatically be measured in HCM series. Proportion of non-compacted myocardium is increased in 
female, non-obstructives, and in those with lower contractility. The amount of trabeculation might help to identify HCM patients prone to systolic heart failure.

Keywords: advanced cardiac imaging; hypertrophic cardiomyopathy; myocardial disease; cardiac magnetic resonance; left ventricular non-compaction; trabeculas

\section{Introduction}

Hypertrophic cardiomyopathy (HCM) is a genetic cardiac disease characterized by clinical and prognostic heterogeneity [1-4]. The variable phenotypic expression and incomplete penetrance [5] have constituted an obstacle to obtain a full understanding of the consequences of the disease. HCM is mainly caused by mutations in genes encoding sarcomeric contractile proteins $[6,7]$.

Left ventricular non-compaction (LVNC) is defined by an increase of trabeculations in the left ventricular endo-myocardium. Adult appearance of trabeculated myocardium may mainly be a consequence of an arrest in the embryologic process of compaction.

Some authors have suggested that myocardial trabeculations can be acquired (although this hypothesis remains to be demonstrated) in response to an increase in cardiac load [8,9].

This entity was increasingly recognized with the development of high definition cardiac imaging. Although LVNC can be in isolation, an increase in hypertrabeculation often accompanies other genetic cardiomyopthies [10]. Despite early descriptions of LVNC in adults showed an increase in the rate of adverse outcomes, such as progression to heart failure, arrhythmias, and emboli [11,12], further analysis has showed inconsistent results [13-15].

The clinical relevance of the presence of hypertrabeculation in HCM is unknown. We aim to measure the left ventricular mass and proportion of trabeculation in a population of $\mathrm{HCM}$ patients.

\section{Materials and Methods}

\subsection{Study Sample}

Patients recruited from an Inherited Cardiomyopathy Clinic-meeting international HCM criteria with an available good quality CMR study-were included. The first CMR of each patient was used for the study. Clinical and outcome data prospectively collected in a database was available for analysis.

Patients were prospectively included, cardiac imaging and examinations were performed prospectively; symptoms, history of hypertension (HTN), regular physical exercise and arrhythmic events prior to the first evaluation were also recorded. HTN was defined following European Society of Hypertension and European Society of Cardiology recommendation [16].

Echocardiographic variables included: pattern of left ventricular hypertrophy (LVH) [17]; maximal left ventricular wall thickness (MWT); LV mass (Devereaux); LV systolic and diastolic diameters; left atrium diameter (LA); LV systolic and diastolic function (systolic dysfunction was considered if LVEF was $<50 \%$ ); left ventricular outflow tract gradient (LVOTG) and the presence of mitral regurgitation. LVOT obstruction was defined as LVOTG $>30 \mathrm{mmHg}$.

All patients were offered a $24 \mathrm{~h}$ ECG-Holter and exercise test in order to complete sudden death (SD) risk stratification. Non-sustained ventricular tachycardia (NSVT) was assessed. Arrhythmic events and complications during follow up were also recorded. In the cohort, there were three resuscitated cardiac arrests (CA) and six appropriate implantable cardioverter defibrillator (ICD) discharges, which were computed as SD equivalent for survival estimates. Mean follow-up was $49.1 \pm 37.1$ months (Figure 1).

All subjects gave their informed consent for inclusion before they participated in the study. The study was conducted in accordance with the Declaration of Helsinki, and the protocol was approved 
by the Ethics Committee of Clinical Research from Universitary Hospital Virgen de la Arrixaca (218/C/2015).

(A)

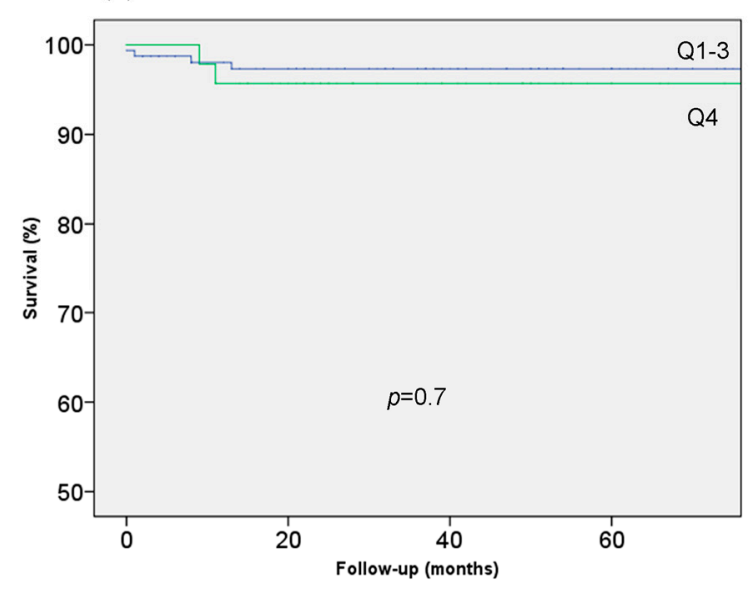

(B)

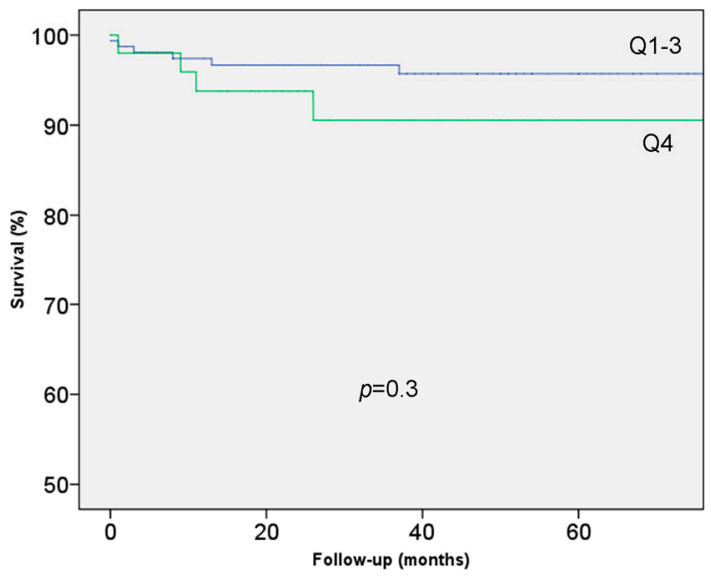

Figure 1. Survival for higher trabeculated myocardium (TM\%) quartile (Kaplan Meier curves). (A) Sudden Death (SD) equivalent; (B) CV death.

\subsection{Trabecular Quantification}

Magnetic resonance studies were performed in two hospitals with different scanners: SIGNA HDxt 1,5T: General Electric Systems, USA, post-processing software Advantage Workstation, AWA.3-08 and Achieva CV, Philips Medical Systems, Netherlands, (Philips Software workspace 2.6.3.2). A dedicated software tool for the automatic quantification and exact hyper-trabeculation degree of LVNC based on automatic delineation of the epicardial and endocardial borders of the LV and trabecular recesses was used [18] (see Supplementary Materials) (Figure 2).

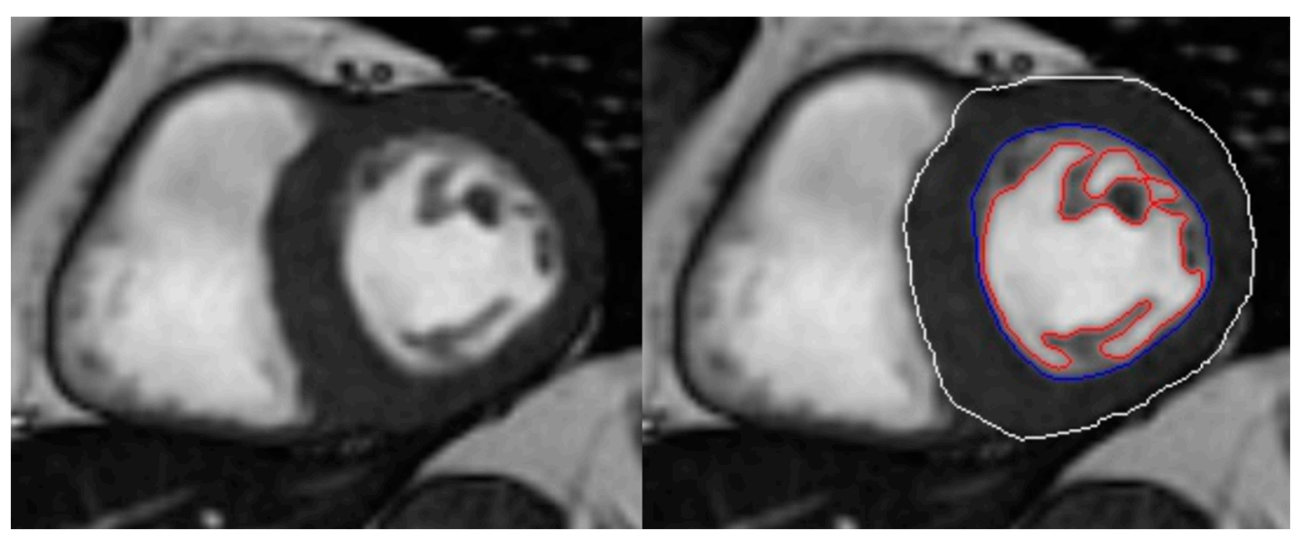

Figure 2. Example of automatic quantification of the compacted and trabeculated myocardium. Left: still diastolic coronal CMR image. Right: automatic border delineation of compacted and trabeculated myocardium from the same slice. White: epicardial border, blue: endocardial border, red: trabeculation border.

Performance of the software was reviewed visually by one imaging cardiologist expert in order to rule out significant deviations. Additionally, delineation of the borders of 10 randomly selected cases was subjectively scored by two skilled cardiologists. The score went from 1 to 5 , from large disagreement (1) to exact match (5). A total of $73 \mathrm{CMR}$ slices were evaluated: 65 slices were scored with a five by the two and the remaining eight slices were classified with a four at least by one of the 
cardiology experts. The weighted kappa statistic showed an agreement between the two observers of 96.6\% (kappa 0.76).

\subsection{Statistical Analysis}

Statistical analysis was performed using SPSS statistical software (version 21.0 IBM Corp. Chicago, IL, USA, 2012). Chi square, $t$-test, Anova and Pearson were used for comparison between groups where appropriate. Variables with $p<0.10$ in univariate were included in the multivariate analysis. Additionally, those considered relevant to adjust the model were also included. Variables with redundant information or colinearity were excluded. Linear logistic regression was used for association between study variables (TM and TM\%) and clinical variables. Kaplan Meier estimates and Cox regression analysis were used for survival analysis. $p$-values $<0.05$ were considered statistically significant.

\section{Results}

The study population comprised $211 \mathrm{HCM}$ patients (mean age $47.8 \pm 16.3$ years old, 154, $73 \%$ males).

Baseline clinical characteristics of patients included in the study regarding the quartile of trabeculation, are summarized in Table 1 . Reason for diagnosis was symptoms in $88(47.0 \%)$, screening in $51(24.2 \%)$, incidental or unknown $71(33.6 \%)$ and SD in $1(0.5 \%) .43(20.5 \%)$ were symptomatic, with $30(14.2 \%)$ of patients in NYHA III-IV and $13(6.3 \%)$ syncope. $42(19.9 \%)$ had history of atrial fibrillation (AF), and 39 (19.8\%) NSVT on ECG-Holter monitoring.

Table 1. Demographics and clinical characteristics per trabeculation quartile*.

\begin{tabular}{|c|c|c|c|c|c|c|c|}
\hline & & Q1 & Q2 & Q3 & Q4 & Total & Sig. $(p)$ \\
\hline $\mathrm{n}$ & & $54(25.6)$ & $51(24.2)$ & $54(25.6)$ & $52(24.6)$ & $211(100.0)$ & \\
\hline Age at diagnosis & & $45.8 \pm 15.5$ & $42.5 \pm 17.8$ & $43.2 \pm 17.0$ & $45.9 \pm 18.8$ & $44.4 \pm 17.2$ & 0.668 \\
\hline Age at CMR & & $50.6 \pm 14.9$ & $48.2 \pm 17.9$ & $47.4 \pm 16.5$ & $53.1 \pm 15.2$ & $49.8 \pm 16.2$ & 0.267 \\
\hline Proband & & $41(75.9)$ & $32(62.7)$ & $40(74.1)$ & $28(53.8)$ & $141(66.8)$ & 0.059 \\
\hline \multirow{2}{*}{ Sex } & Male & $38(70.4)$ & $39(76.5)$ & $39(72.2)$ & $38(73.1)$ & $154(73)$ & 0.880 \\
\hline & Female & $16(29.6)$ & $12(23.5)$ & $15(27.8)$ & $14(26.9)$ & $57(27)$ & 0.880 \\
\hline \multirow{4}{*}{ Reason for diagnosis } & Incidental & $18(33.3)$ & $18(29.4)$ & $16(29.6)$ & $12(23.1)$ & $61(28.9)$ & 0.275 \\
\hline & Symptoms & $25(46.3)$ & $19(37.3)$ & $24(44.4)$ & $20(38.5)$ & $88(41.7)$ & 0.586 \\
\hline & Screening & $9(16.7)$ & $15(29.4)$ & $13(24.1)$ & $14(26.9)$ & $51(24.2)$ & 0.326 \\
\hline & SD & $1(1.9)$ & $0(0.0)$ & $0(0.0)$ & $0(0.0)$ & $1(0.5)$ & 0.183 \\
\hline \multirow{4}{*}{ Genetics } & Positive & $20(37.0)$ & $18(35.3)$ & $26(48.1)$ & $21(40.4)$ & $85(40.3)$ & 0.537 \\
\hline & МYВРС3 & $10(50.0)$ & $11(61.1)$ & $20(76.9)$ & $14(66.7)$ & $55(64.7)$ & 0.136 \\
\hline & MYH7 & $7(35.0)$ & $3(16.7)$ & $1(3.8)$ & $3(14.3)$ & $14(14.5)$ & 0.135 \\
\hline & Other & $3(15.0)$ & $4(22.2)$ & $5(19.2)$ & $3(14.3)$ & $13(15.3)$ & 0.866 \\
\hline HTN & & $20(37.0)$ & $23(45.1)$ & $22(40.7)$ & $22(42.3)$ & 87 (41.2) & 0.698 \\
\hline Physical activity & & $13(24.5)$ & $16(32.0)$ & $27(50.9)$ & $23(45.1)$ & 79 (38.2) & 0.007 \\
\hline Athlete & & $2(3.8)$ & $5(10.0)$ & $11(20.8)$ & $5(9.8)$ & $23(11.1)$ & 0.131 \\
\hline \multirow{4}{*}{ NYHA } & I & $32(61.5)$ & $36(73.5)$ & $37(69.8)$ & $39(76.5)$ & $144(70.2)$ & 0.147 \\
\hline & II & $16(30.8)$ & $13(26.5)$ & $13(24.5)$ & $9(17.6)$ & $51(24.9)$ & 0.126 \\
\hline & III & $3(5.8)$ & $0(0.0)$ & $2(3.8)$ & $2(3.9)$ & $7(3.4)$ & 0.859 \\
\hline & IV & $1(1.9)$ & $0(0.0)$ & $0(0.0)$ & $1(2.0)$ & $2(1.0)$ & 0.998 \\
\hline Syncope & & $4(7.7)$ & $4(8.2)$ & $3(5.7)$ & $2(3.8)$ & $13(6.3)$ & 0.356 \\
\hline
\end{tabular}


Table 1. Cont

\begin{tabular}{ccccccc}
\hline & Q1 & Q2 & Q3 & Q4 & Total & Sig. $(p)$ \\
\hline Atrial Fibrillation & $11(20.4)$ & $10(19.6)$ & $12(22.2)$ & $9(17.3)$ & $42(19.9)$ & 0.794 \\
\hline SD RISK FACTOR & & & & & & \\
\hline FHSCD & $4(7.4)$ & $10(19.6)$ & $5(9.3)$ & $7(13.5)$ & $26(12.3)$ & 0.684 \\
\hline ABPR & $6(14.3)$ & $5(12.8)$ & $9(20.9)$ & $3(7.1)$ & $23(13.9)$ & 0.580 \\
\hline NSVT & $16(30.2)$ & $9(18.4)$ & $9(18.8)$ & $5(10.6)$ & $39(19.8)$ & 0.020 \\
\hline Sustained VT & $2(3.7)$ & $3(5.9)$ & $1(1.9)$ & $0(0.0)$ & $6(2.8)$ & 0.144 \\
\hline
\end{tabular}

${ }^{*}$ Distribution of quartiles is adjusted by gender. FHSCD: Family history of sudden cardiac death (aged $<45$ years old); ABPR: Abnormal blood pressure response on exercise test; HTN: Hypertension; NSVT: Non-sustained ventricular tachycardia; SD, sudden death; physical activity: Significant regular physical activity of $>70 \%$ maximal exercise, for at least $3 \mathrm{~h}$ per week during the last 2 years before first evaluation. Athlete: Intense regular physical activity of $>70 \%$ of maximal exercise, for at least $5 \mathrm{~h}$ per week during the last 2 years before first evaluation.

\subsection{Echocardiography}

Mean maximal LVH was $18.8 \pm 5.1 \mathrm{~mm} .103(50.2 \%)$ of patients with asymmetric LVH, and 64 $(30.5 \%)$ demonstrated obstruction (Table 2 ).

Table 2. Morphological and functional characteristics per trabeculation quartiles *.

\begin{tabular}{cccccccc}
\hline & & Q1 & Q2 & Q3 & Q4 & Total & Sig. (p) \\
\hline Max LVH $(\mathrm{mm})$ & & $21.1(5.1)$ & $19.5(6.3)$ & $18.1(4.0)$ & $16.3(3.1)$ & $18.8(5.1)$ & $<0.001$ \\
\hline \multirow{2}{*}{ Pattern of hypertrophy } & ASH & $27(51.9)$ & $21(44.7)$ & $25(46.3)$ & $30(57.7)$ & $103(50.2)$ & 0.551 \\
\cline { 2 - 7 } & Concentric & $10(19.2)$ & $11(23.4)$ & $17(31.5)$ & $13(25.0)$ & $51(24.9)$ & 0.537 \\
\cline { 2 - 7 } & Apical & $5(9.6)$ & $7(14.9)$ & $3(5.6)$ & $0(0.0)$ & $15(7.3)$ & 0.032 \\
\cline { 2 - 7 } & Reverse & $14(28.0)$ & $7(14.9)$ & $6(11.1)$ & $3(5.8)$ & $30(14.8)$ & 0.012 \\
\cline { 2 - 7 } & Neutro & $13(26.0)$ & $18(38.3)$ & $25(46.3)$ & $29(55.8)$ & $85(41.9)$ & 0.018 \\
\hline Sigmoid & $3(6.0)$ & $3(6.4)$ & $4(7.4)$ & $4(7.7)$ & $14(6.9)$ & 0.985 \\
\hline Severe Obstruction & & $25(47.2)$ & $13(25.5)$ & $16(29.6)$ & $10(19.2)$ & $64(30.5)$ & 0.005 \\
\hline LVED $(\mathrm{ml})$ & & $12(22.2)$ & $6(12.0)$ & $5(9.3)$ & $4(8.0)$ & $27(13.0)$ & 0.027 \\
\hline LVES $(\mathrm{ml})$ & & $158.1(49.0)$ & $154.5(40.1)$ & $165.1(32.9)$ & $171.5(57.4)$ & $162.5(46.0)$ & 0.281 \\
\hline LVEF $(\%)$ & $53.7(37.6)$ & $51.4(20.7)$ & $58.5(25.3)$ & $71.9(47.3)$ & $59.1(35.2)$ & 0.019 \\
\hline LVEF < 50\% & & $67.9(10.7)$ & $67.2(7.5)$ & $64.5(11.4)$ & $60.1(14.4)$ & $64.8(11.7)$ & 0.004 \\
\hline LGE & & $2(4.2)$ & $3(6.3)$ & $6(11.8)$ & $8(16.3)$ & $19(9.7 \%)$ & 0.023 \\
\hline
\end{tabular}

* Distribution of quartiles is adjusted by gender. Max LVH: maximal left ventricular hypertrophy (mm) from echocardiography, Obstruction: Left ventricular out flow tract gradient at rest or Valsalva of $>30 \mathrm{mmHg}$ estimated from echocardiography, Severe obstruction: Left ventricular out flow tract gradient at rest or Valsalva of $>30 \mathrm{mmHg}$ estimated from echocardiography. LVED: left ventricular end diastolic volume (ml) from CMR, LVES: Left ventricular end systolic volume (ml) from CMR, LVEF: Left ventricular ejection fraction (\%) from CMR, LGE: Late gadolinium enhancement on CMR.

\subsection{Trabeculation and Demographics}

Despite both trabeculated (TM) and compacted myocardial (CM) mass were increased in males compared to females, females had significantly higher TM\% $(29.7 \%$ vs. $25.6 \%, p<0.0001)$. Indexed CM remained increased in males compared to females while TM mass was similar in males and females (Table 3).

There was no association between age and TM\%. TM\% was similar in $87 \mathrm{HTN}$ versus 124 non-HTN patients with HCM $(27.2 \pm 6.1 \%$ vs. $26.4 \pm 6.7 \%, p=0.4)$ and in 23 patients who performed versus 181 who did not engage in intense physical activity $(27.0 \pm 4.6 \%$ vs. $26.7 \pm 6.6 \%, p=0.7)$. 
Table 3. Cardiac magnetic resonance trabecular parameters by gender.

\begin{tabular}{ccccc}
\hline & Female & Male & Total & Sig. $(p)$ \\
\hline CM & $124.8 \pm 55.5$ & $173.1 \pm 59.3$ & $160.0 \pm 62.0$ & $<0.0001$ \\
\hline TM & $49.8 \pm 18.5$ & $57.6 \pm 18.5$ & $55.5 \pm 18.7$ & 0.007 \\
\hline TM\% & $29.7 \pm 7.2$ & $25.6 \pm 5.8$ & $26.7 \pm 6.4$ & $<0.0001$ \\
\hline CM (indexed) & $72.2 \pm 32.0$ & $87.9 \pm 30.1$ & $83.6 \pm 31.3$ & 0.001 \\
\hline TM (indexed) & $29.1 \pm 11.6$ & $29.1 \pm 9.3$ & $29.1 \pm 10.0$ & 0.977 \\
\hline
\end{tabular}

CM: Compacted myocardium (g). TM: Trabeculated myocardium (g). TM\%: Proportion of trabeculated myocardium.

\subsection{Trabeculation and Morphological Findings}

Correlation between TM\% and main variables from CMR are illustrated in Figure 3. An inverse correlation between MWT and TM\% was observed (Pearson $-0.40, p<0.0001$ ) (Figure 3B). Patients with severe LVH (MWT $\geq 30 \mathrm{~mm}$ ) had similar TM but significantly lower TM\% compared to non-severe ones $(20.0 \pm 4.9 \%$ vs. $27.0 \pm 6.3 \%, p=0.002)$.
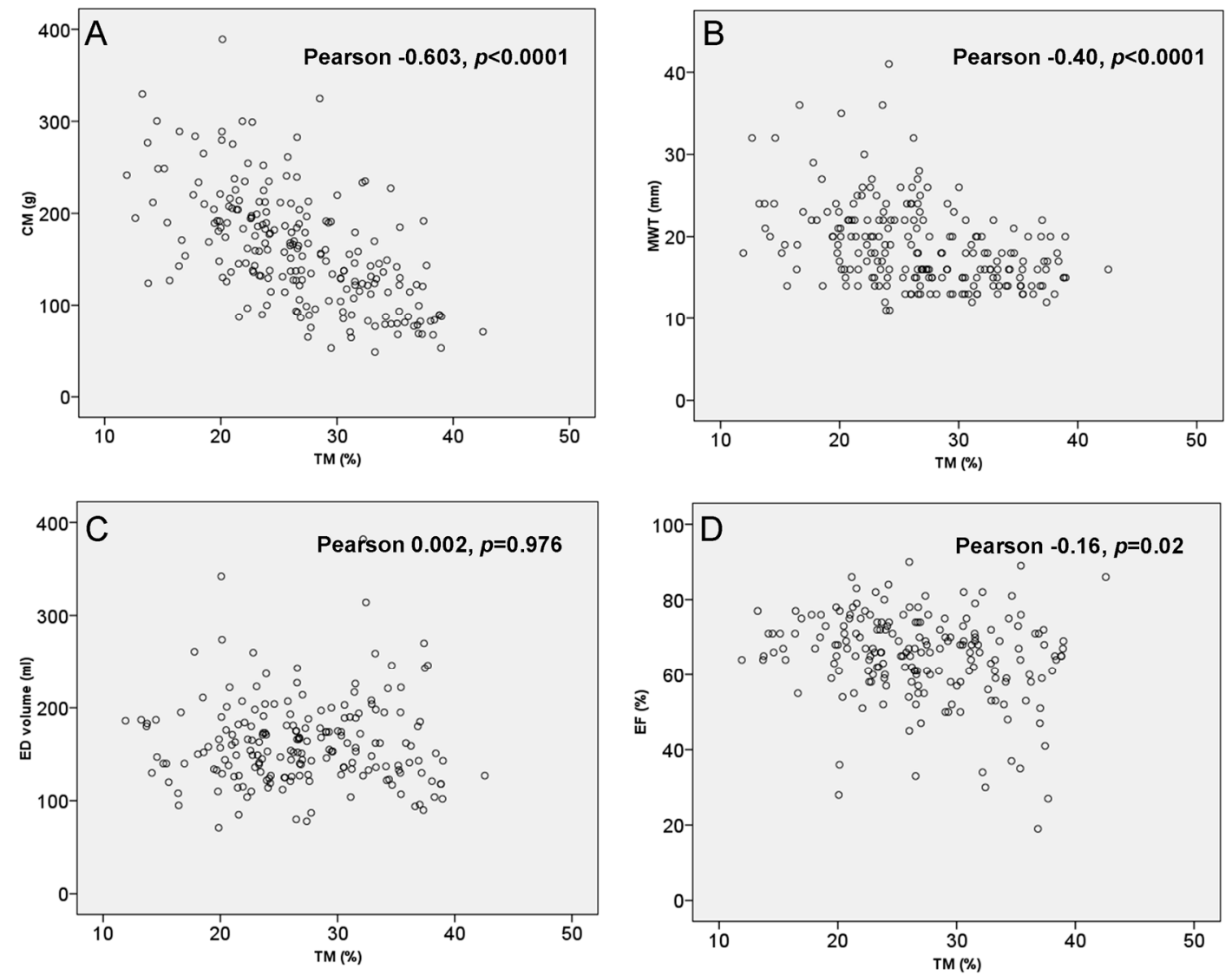

Figure 3. Correlation between TM\%, (A) CM, (B) MWT (from echocardiography), (C) ED volume, and (D) $\mathrm{EF} \%$.

Patients with obstruction had increased CM mass (and indexed CM mass) but reduced TM\% compared to non-obstructives $(184.3 \pm 68.0 \mathrm{~g}$ vs. $149.6 \pm 56.4 \mathrm{~g}, p<0.0001$ and $24.9 \pm 27.6 \%$ vs. $27.6 \pm$ $6.3 \%, p<0.0001$, for CM and TM\%, respectively). Neutral pattern had an increased TM\% $(28.4 \pm 5.9 \%$ vs. $25.8 \pm 6.7 \%, p=0.004$ ), while septal reverse and apical pattern of hypertrophy had significantly less TM\% $(22.4 \pm 6.2 \%$ vs. $27.6 \pm 6.2 \%, p<0.0001$, and $22.8 \pm 3.9 \%$ vs. $27.1 \pm 6.5 \%, p=0.01)$. There was no correlation between left atrium diameter and $\mathrm{TM} \%$. 
No correlation was found between end-diastolic and end-systolic LV volumes from CMR and TM\% (Figure 3C). An inverse correlation was demonstrated between LVEF\% and TM\% (Pearson -0.16 , $p=0.02)$ (Figure 3D). Patients with LVEF $<50 \%$ had higher TM $\%$ values $(30.2 \pm 6.0 \%$ vs. $26.6 \pm 6.4 \%$, $p=0.02)$.

Late gadolinium enhancement (LGE) was associated with CM, TM and TM\% (including indexed parameters). Of the patients, 106 (54.1\%) with positive LGE had significantly higher CM mass (179.4 \pm $61.8 \mathrm{~g}$ vs. $138.4 \pm 56.9 \mathrm{~g}, p<0.0001)$, higher TM $(58.3 \pm 18.5$ vs. $52.3 \pm 19.1 \mathrm{~g}, p=0.03)$ but lower TM\% $(25.3 \pm 5.9 \%$ vs. $28.3 \pm 6.8 \%, 0.001)$, compared to the 90 (45.9\%) with no LGE.

\subsection{Trabeculation and Clinical Findings}

TM\% was not related with symptoms. Patients with dyspnea (NYHA III-IV) or syncope had similar TM and TM\%. There was no difference in TM\% in patients with or without AF. There were only $6(2.8 \%)$ patients with sustained ventricular tachycardia who had a significantly lower TM\% $(19.8 \pm 6.0$ vs. $26.9 \pm 6.3, p=0.007)$.

Nine $(4.3 \%)$ patients who required pacemaker implantation had significantly lower TM\% $(20.2 \pm$ $5.0 \%$ vs. $27.0 \pm 6.3 \%, p=0.002) .26(12.3 \%)$ patients who subsequently underwent ICD implantation seemed to have also lower TM\% $(24.5 \pm 6.3 \%$ vs. $27.0 \pm 6.4 \%, p=0.058)$ (Table 4$)$.

Table 4. Devices and disease related outcomes per trabeculation quartiles *.

\begin{tabular}{ccccccc}
\hline & Q1 & Q2 & Q3 & Q4 & Total & Sig. $(p)$ \\
\hline Pacemaker & $7(13.0)$ & $1(2.0)$ & $0(0.0)$ & $1(1.9)$ & $9(4.3)$ & 0.004 \\
\hline ICD & $9(16.7)$ & $6(11.8)$ & $8(14.8)$ & $3(5.8)$ & $26(12.3)$ & 0.145 \\
\hline Sustained VT & $2(3.7)$ & $3(5.9)$ & $1(1.9)$ & $0(0.0)$ & $6(2.8)$ & 0.144 \\
\hline Stroke & $7(13.0)$ & $1(2.0)$ & $2(3.7)$ & $1(1.9)$ & $11(5.3)$ & 0.020 \\
\hline Transplant & $0(0.0)$ & $0(0.0)$ & $0(0.0)$ & $1(1.9)$ & $1(0.5)$ & 0.178 \\
\hline SD & $2(3.7)$ & $3(5.9)$ & $1(1.9)$ & $2(3.8)$ & $8(3.8)$ & 0.762 \\
\hline HF Death & $1(1.9)$ & $0(0.0)$ & $0(0.0)$ & $1(1.9)$ & $2(0.9)$ & 0.993 \\
\hline CV death & $3(5.6)$ & $3(5.9)$ & $2(3.7)$ & $4(7.7)$ & $12(5.7)$ & 0.774 \\
\hline
\end{tabular}

* Distribution of quartiles is adjusted by gender. ICD, implantable cardioverter defibrillator, VT: Ventricular tachycardia, SD: Sudden death (includes sudden death, resuscitated cardiac arrest and ICD appropriate therapy), HF death: Heart failure death (included heart failure death and cardiac transplant), CV death: Cardiovascular death (includes SD, HF death, stroke related death and other disease related deaths).

Eleven (5.2\%) patients who developed a stroke had lower TM\% than those who did not $(22.7 \pm 7.9 \%$ vs. $26.9 \pm 6.3 \%, p=0.03)$.

In total, $12(5.7 \%)$ patients had at least one major event over a mean $49.1 \pm 37.1$ months of follow-up: three patients died suddenly, one had a resuscitated cardiac arrest and four had appropriate ICD therapies. There was one heart failure death, one stroke related death, one procedure related death, and one heart transplant.

The eight patients with SD (or equivalent) had significantly higher CM (224.8 $\pm 77.6 \mathrm{~g}$ vs. $157.5 \pm$ $60.1 \mathrm{~g}, p=0.02)$ and TM mass $(75.1 \pm 23.1 \mathrm{~g}$ vs. $54.7 \pm 18.2 \mathrm{~g}, p=0.002)$ but similar TM\% $(25.4 \pm 5.1 \%$ vs. $26.8 \pm 6.5 \%, p=0.5)$. TM\% was not associated with the combined major outcome.

\subsection{Multivariable Analysis}

Female gender, MWT, neutral pattern of hypertrophy, obstruction, and LVEF were associated with $\mathrm{TM} \%$ on multivariable analysis which included morphologic and demographic predictors. Age, HTN, physical exercise, left atrium diameter, or the presence of LGE were not associated with TM\% (Table 5) . 
Table 5. Variables associated with trabeculated myocardium (\%) on multivariable analysis.

\begin{tabular}{cccc}
\hline & Beta & $\mathbf{9 5 \%}$ CI & Sig. $(p)$ \\
\hline Female & 4.294 & $(2.466,6.122)$ & $<0.0001$ \\
\hline LVEF (\%) & -0.124 & $(-0.195,-0.053)$ & 0.0007 \\
\hline Obstruction (absence) & 1.819 & $(0.043,3.595)$ & 0.0448 \\
\hline MWT (mm) & -0.423 & $(-0.605,-0.242)$ & $<0.0001$ \\
\hline Pattern (neutre) & 1.725 & $(0.021,3.429)$ & 0.0473 \\
\hline
\end{tabular}

Symptoms (syncope or dyspnea) were not associated with TM\% in a model with demographic, main morphological variables and symptoms. AF and NSVT on Holter was neither associated with $\mathrm{TM} \%$.

On multivariable analysis TM\% was not associated with cardiovascular (CV) death or equivalent. MWT and AF were the only two variables associated with CV death.

In the presence of CM mass calculated from CMR, MWT lost his value in the prediction of CV death. In this model, AF remained significantly associated (and a trend of TM\%) (Table 6).

Table 6. Variables associated with cardiovascular death (or equivalent) on multivariable analysis.

\begin{tabular}{cccc}
\hline & $\operatorname{Exp}(\mathbf{B})$ & $\mathbf{9 5 \%}$ CI & Sig. $(p)$ \\
\hline Compacted myocardium $(\mathrm{g})$ & 1.011 & $(1.002,1.021)$ & 0.0197 \\
\hline Atrial Fibrillation & 8.914 & $(2.267,35.050)$ & 0.0017 \\
\hline
\end{tabular}

Severity of wall thickness, measured as MWT or CM mass were the strongest predictors of CV death and SD.

\section{Discussion}

This is the first study to systematically quantify LV trabeculation in an HCM population. The main finding from our study was that a clinical profile of patients with HCM with increased trabeculations may exist. Some of the features were predominant female gender, and non-obstructive forms with systolic impairment. There was no association between TM with age, ventricular volumes, or LGE. Higher degree of trabeculation in HCM was associated with LVEF below $50 \%$ which might precede development of systolic heart failure [19]. Degree of trabeculations do not seem to associate to an increase arrhythmic risk in HCM. A longer follow up is needed confirm these findings.

Jacquier et al. [20] manually measured the TM mass in a group of patients with isolated non-compaction, dilated cardiomyopathy, HCM, and controls. A threshold of 20\% of TM was proposed as a good cutoff for the diagnosis of LVNC ( $\mathrm{S}$ and E >93\%). Sixteen LVNC patients had an average of trabeculated mass of $32 \%$, compared to $11 \%$ to $12 \%$ of DCM, HCM and controls. In this paper, the 16 patients with $\mathrm{HCM}$ had a mean CM of $216 \mathrm{~g}$, which is significantly higher to the one measured in our study $(160.0 \pm 62.0 \mathrm{~g})$. On the contrary, trabeculated myocardial mass was lower in that paper compared to our estimation from 211 patients ( $28 \mathrm{~g}$ vs. $55.5 \pm 18.7 \mathrm{~g}$ ). In Jacquier's paper, papillary muscles were manually excluded from the TM, while in our automatic measurement this was included. Observed differences cannot solely be explained by different methodology [21].

The percentage of trabeculated myocardium showed in this large series of HCM $(26.7 \pm 6.4 \%)$ patients demonstrate a clear increase from that observed in controls, which suggests that LVNC or hypertrabeculation is part of the clinical phenotype of HCM. In an earlier paper from our group using the same software, a cutoff of $27 \%$ MT showed to have a good accuracy for differentiation of LVNC [22].

In contrast to the fractal analysis recently published by Captur et al. [23], based on tortuosity measured by pixelation of the line of the endocardial border, our software provides easy to understand clinical measurements of CM and TM mass. This computationally-assisted method could save valuable 
diagnostic time compared with traditional processing, thus minimizing the possibility of human error. We demonstrate also in this population of HCM patients, a good performance of the software for quantification of hypertrabeculation based on the automatic delineation of borders from CMR diastolic images [24].

Trabeculation in its different forms, including deep crypts and clefts has been suggested to be a pre-diagnostic (maybe congenital) feature in carriers of HCM associated mutations [25]. While other authors suggest an acquired mechanism [26], from observations of increases of trabeculation in high demanding conditions such as in athletes and pregnancy, the mechanism of how this occurs is however unknown. Moreover, a reversion of the phenotype with the normalization in cardiac load after delivery, has been shown in one of those studies [27]. We have failed to show any association between the degree of physical activity, presence of HTN, or obstruction in the magnitude of trabeculations in our series of HCM patients.

In contrast with an early paper of a dilated cardiomyopathy series [28], which suggested a higher rate of stroke in patients with LVNC, we also failed to demonstrate association between embolic events in higher trabeculated ventricles with HCM.

To finalize, we want to highlight the need of a quantification of trabeculation in order to define the limits between normality and abnormality and to establish the role of non-compaction in various cardiac conditions. Our software has demonstrated to be useful not only for automatic quantification of $\mathrm{TM}$ but also for CM. In this regard, in our study, CM mass measured by the software was the strongest predictor of the outcome above the traditional maximal wall thickness taken from echocardiography. The latter supports the use of global assessment of left ventricular CM and TM mass to replace focal measurements of wall thickness in risk algorithms.

\section{Limitations}

Differences in the characteristics of our series regarding distribution of the pattern of hypertrophy, value of LVH mass, proportion of obstruction or percentage of LGE might be due to the age of the cohort, which is relatively young (mean 44 years old), the inclusion of a $~ 34 \%$ of relatives (as compared to probands) or the relatively high percentage of patients diagnosed through family screening $(25 \%)$ or incidentally $(28 \%)$. Further studies are warranted to verify our findings.

Despite the number of individuals being relatively large, only a few patients developed CV events. Survival analysis is then limited, and results should be taken carefully. Patients with devices were ruled out from CMR and some high-risk patients were excluded. Repeated CMR studies were not available and changes over follow-up in CM and TM could not be explored.

Genetic information was available in $88 / 140(62.9 \%)$ of the probands included in the cohort. Genetic testing yield was $43 / 88(48.9 \%)$. Further analysis of the association between genetic results and morphologic and clinical findings was not performed due to the incompleteness of the genetic information.

\section{Conclusions}

A significant proportion ( $25 \%$ ) of myocardium appears non-compacted and can be automatically measured in HCM series. There is a clinical profile of patients with HCM with increased trabeculations. Proportion of non-compacted myocardium is increased in female, non-obstructives, and in those with lower contractility. The amount of trabeculation might help to identify HCM patients prone to systolic heart failure. Amount of trabeculation does not seem to associate with arrhythmias.

Supplementary Materials: The following are available online at http://www.mdpi.com/2077-0383/9/10/3171/s1, S1 File: Magnetic resonance studies.

Author Contributions: Conceptualization, J.D.C., J.G.C. and G.B.G.; methodology, G.B.G. and J.G.C.; software, J.D.C., J.C.M. and G.B.G.; validation, J.D.C., J.M.J. and J.G.C.; formal analysis, J.D.C. and J.G.C.; investigation, J.L.d.l.P., M.S.A., R.E. and Á.R.; resources, J.L.P., Á.R.; data curation, J.M.J., J.C.M., C.M.E., E.B.M. and J.R.G.; writing—original draft preparation, J.G.C. and J.R.G.; writing—review and editing, G.B.G., M.S.M.; visualization, 
J.R.G.; supervision, J.J.J. and M.S.M.; project administration, M.S.M. and J.R.G.; funding acquisition, J.L.P. Á.R. and J.R.G. All authors have read and agreed to the published version of the manuscript.

Funding: This work was supported by a grant from the Foundation Marató TV3 2018/C/2015 and by the Spanish MICINN and AEI, as well as European Commission FEDER funds, under grant RTI2018-098156-B-C53. Investigators are part of the cardiovascular research network and Cell Therapy network (TerCel) of the Carlos III Health Institute (SAF2015-71863-REDT, RTI2018-095377-B-I00, CIBERCV CB16/11/00385, RD16/0011/0021, RD16/0011/0024, CB16/11/00399, RIC; RD12/0042/0049), MCIU (SAF2016-78370-R) and IMIB (Instituto Murciano de Investigación Biosanitaria). María Sabater was supported by a grant from FFIS. Investigators are part of clinical group of ERN Guard-Heart, CIBERCV, CIBERER and University of Murcia.

Acknowledgments: The authors would like to thank David López Cuenca, Elisa Nicolás, Maria José Oliva Sandoval, and Daniel Saura Espin for their help in both the clinical and molecular work of this project.

Conflicts of Interest: The authors declare no conflict of interest. The funders had no role in the design of the study; in the collection, analyses, or interpretation of data; in the writing of the manuscript, or in the decision to publish the results.

\section{References}

1. Elliott, P.M.; Anastasakis, A.; Borger, M.A.; Borggrefe, M.; Cecchi, F.; Charron, P.; Hagege, A.A.; Lafont, A.; Limongelli, G.; Mahrholdt, H.; et al. 2014 ESC Guidelines on diagnosis and management of hypertrophic cardiomyopathy: The Task Force for the diagnosis and management of hypertrophic cardiomyopathy of the European Society of Cardiology (ESC). Eur. Heart J. 2014, 35, 2733-2779. [CrossRef] [PubMed]

2. Maron, B.J. Hypertrophic cardiomyopathy: A systematic review. JAMA 2002, 287, 1308-1320. [CrossRef] [PubMed]

3. Spirito, P.; Seidman, C.E.; McKenna, W.J.; Maron, B.J. The management of hypertrophic cardiomyopathy. N. Engl. J. Med. 1997, 336, 775-785. [CrossRef]

4. Elliott, P.; McKenna, W.J. Hypertrophic cardiomyopathy. Lancet 2004, 363, 1881-1891. [CrossRef]

5. Charron, P.; Carrier, L.; Dubourg, O.; Tesson, F.; Desnos, M.; Richard, P.; Bonne, G.; Guicheney, P.; Hainque, B.; Bouhour, J.B.; et al. Penetrance of familial hypertrophic cardiomyopathy. Genet. Couns. 1997, 8, 107-114.

6. Seidman, J.G.; Seidman, C. The genetic basis for cardiomyopathy: From mutation identification to mechanistic paradigms. Cell 2001, 104, 557-567. [CrossRef]

7. Gómez, J.; Rqguero, J.R.; Coto, E. The ups and downs of genetic diagnosis of hypertrophic cardiomyopathy. Rev. Esp. Cardiol. 2016, 69, 61-68. [CrossRef]

8. Arbustini, E.; Favalli, V.; Narula, N.; Serio, A.; Grasso, M. Left ventricular non-compaction. A distinct genetic cardiomyopapthy? J. Am. Coll. Cardiol. 2016, 68, 949-966. [CrossRef] [PubMed]

9. Oechslin, E.; Jenni, R. Left ventricular noncompaction. From physiologic remodeling to noncompaction cardiomyopathy. J. Am. Coll. Cardiol. 2018, 71, 723-726. [CrossRef]

10. Finsterer, J.; Stöllberger, C.; Towbin, J.A. Left ventricular noncompaction cardiomyopathy: Cardiac, neuromuscular, and genetic factors. Nat. Rev. Cardiol. 2017, 14, 224-237. [CrossRef]

11. Chin, T.K.; Perloff, J.K.; Williams, R.G.; Jue, K.; Mohrmann, R. Isolated noncompaction of the left ventricular myocardium. A study of eight cases. Circulation 1990, 82, 507-513. [CrossRef]

12. Oechslin, E.N.; Attenhofer Jost, C.H.; Rojas, J.R.; Kaufmann, P.A.; Jenni, R. Long-term follow-up of 34 adults with isolated left ventricular noncompaction: A distinct cardiomyopathy with poor prognosis. J. Am. Coll. Cardiol. 2000, 36, 493-500. [CrossRef]

13. Dedaghat-Hamedani, F.; Haas, J.; Zhu, F.; Geier, C.; Kayvanpour, E.; Liss, M.; Lai, A.; Frese, K.; Pribe-Wolferts, R.; Amr, A.; et al. Clinical genetics and outcome of left ventricular non-compaction cardiomyopathy. Eur. Heart J. 2017, 38, 3449-3460. [CrossRef]

14. Hussein, A.; Karimianpour, A.; Collier, P.; Krasuski, R.A. Isolated noncompaction of the ventricle in adults. J. Am. Coll. Cardiol. 2005, 66, 578-585. [CrossRef] [PubMed]

15. van Waning, J.I.; Caliskan, K.; Hoedemaekers, Y.M.; van Spaendonck-Zwarts, K.Y.; Baas, A.F.; Boekholdt, S.M.; van Melle, J.P.; Teske, A.J.; Asselbergs, F.W.; Backx, A.P.C.M.; et al. Genetics, clinical features, and long-term outcome of noncompaction cardiomyopathy. J. Am. Coll. Cardiol. 2018, 71, 711-722. [CrossRef]

16. Williams, B.; Mancia, G.; Spieling, W.; Agabiti, E.; Azizi, M.; Burnier, M.; Clement, D.L.; Coca, A.; de Simone, G.; Dominiczak, A.; et al. 2018 ESC/ESH Guidelines for the management of arterial hypertension. Eur. Heart J. 2018, 39, 3021-3104. [CrossRef] [PubMed] 
17. Geske, J.B.; MartijnBos, J.; Gersh, B.J.; Ommen, S.R.; Eidem, B.W.; Ackerman, M.J. Deformation patterns in genotyped patients with hypertrophic cardiomyopathy. Eur. Heart J. Cardiovasc. Imaging 2014, 15, 456-465. [CrossRef] [PubMed]

18. Bernabé, G.; Cuenca, J.; de Teruel, P.E.L.; Giménez, D.; González-Carrillo, J. A software tool for the automatic quantification of the LV myocardium hypertrabeculation degree. Procedia Comput. Sci. 2015, 51, 610-619. [CrossRef]

19. Thaman, R.; Gimeno, J.R.; Murphy, R.T.; Kubo, T.; Sachdev, B.; Mogensen, J.; Elliott, P.M.; McKenna, W.J. Prevalence and clinical significance of systolic impairment in hypertrophic Cardiomyopathy. Heart 2005, 91, 920-925. [CrossRef] [PubMed]

20. Jacquier, A.; Thuny, F.; Jop, B.; Giorgi, R.; Cohen, F.; Gubert, J. Measurement of trabeculated LV mass using CMR imaging in the diagnosis of LVNC. Eur. Heart J. 2010, 31, 1098-1104. [CrossRef] [PubMed]

21. Papavasilliu, T.; Kuhl, H.P.; Schroder, M.; Susalbeck, Y.; Bondareu, K.O.; Bohn, C.K.; Beek, A.; Hofman, M.M.B.; van Rossum, A.C. Effect of endocardial trabeculae on left ventricular measurements and measurement reproducibility at cardiovascular MR imaging. Radiology 2005, 236, 57-64. [CrossRef]

22. Bernabé, G.; González-Carrillo, J.; Cuenca, J.; Rodríguez Sánchez, D.; Saura-Espín, D.; Gimeno, J.R. Performance of a new software tool for automatic quantification of left ventricular trabeculations. Rev. Esp. Cardiol. 2017, 70, 405-407. [CrossRef] [PubMed]

23. Captur, G.; Lopes, L.R.; Patel, V.; Li, C.; Bassett, P.; Syrris, P. Abnormal cardiac formation in hypertrophic cardiomyopathy-Fractal analysis of trabeculae and preclinical gene expression. Circ. Cardiovasc. Genet. 2014, 7, 241-248. [CrossRef] [PubMed]

24. Bernabé, G.; Casanova, J.D.; Cuenca, J.; González-Carrillo, J. A self-optimized software tool for quantifying the degree of left ventricle hyper-trabeculation. J. Supercomput. 2019, 75, 1625. [CrossRef]

25. Captur, G.; Ho, C.Y.; Schlossarek, S.; Kerwin, J.; Mirabel, M.; Wilson, R.; Rosmini, S.; Obianyo, C.; Reant, P.; Bassett, P.; et al. The embryological basis of subclinical hypertrophic cardiomyopathy. Sci. Rep. 2016, 21, 27714. [CrossRef] [PubMed]

26. Gati, S.; Chandra, N.; Bennett, R.L.; Reed, M.; Kervio, G.; Panoulas, V.F.; Ghani, S.; Sheikh, N.; Zaidi, A.; Wilson, M.; et al. Increased left ventricular trabeculation in highly trained athletes: Do we need more stringent criteria for the diagnosis of left ventricular non-compaction in athletes? Heart 2013, 99, 401-408. [CrossRef]

27. Gati, S.; Papadakis, M.; Papamichael, N.D.; Zaidi, A.; Sheikh, N.; Reed, M.; Sharma, R.; Thilaganathan, B.; Sharma, S. Reversible de novo left ventricular trabeculations in pregnant women: Implications for the diagnosis of left ventricular non-compaction in low-risk populations. Circulation 2014, 130, 475-483. [CrossRef]

28. Murphy, R.T.; Thaman, R.; Blanes, J.G.; Ward, D.; Sevdalis, E.; Papra, E.; Kiotsekoglou, A.; Tome, M.T.; Pellerin, D.; McKenna, W.J.; et al. Natural history and familial characteristics of isolated left ventricular non-compaction. Eur. Heart J. 2005, 26, 187-192. [CrossRef]

(C) 2020 by the authors. Licensee MDPI, Basel, Switzerland. This article is an open access article distributed under the terms and conditions of the Creative Commons Attribution (CC BY) license (http://creativecommons.org/licenses/by/4.0/). 